\title{
Use of Strain-Hardening Cement-Based Composites (SHCC) for Retrofitting
}

\author{
Steffen Müller ${ }^{1}$ and Viktor Mechtcherine ${ }^{1^{*}}$ \\ ${ }^{1}$ Technische Universität Dresden, Institute of Construction Materials, 01062 Dresden, Germany
}

\begin{abstract}
Strain-hardening cement-based composites (SHCC, or Engineered Cementitious Composites, ECC) were developed in the early 1990th and have been since then an object of numerous investigations which number increases every year. Under tensile loading SHCC exhibit fine and well distributed cracking accompanied by large inelastic deformations prior to reaching ultimate strain capacity. Such behaviour makes SHCC suitable for repair and strengthening. The present article reports on the transfer of SHCC from laboratory tests to a practical application and on monitoring this application over several years. At the laboratory scale, neutron radiography was used to visualize the capillary water suction by a specimen made of a multiple cracked SHCC repair layer and a cracked RC substrate. The obtained results led to a practical implementation on a concrete water reservoir in Germany. The presented project served the purpose of testing the new technology in real scale and investigating challenges arising when laboratory scale is left for a larger one, especially resulting from the real mixing and placement conditions. The application was brought into life by industrial partners under close supervision of the authors. The repair layer is in service for several years now and under observation by the TU Dresden with respect to cracking behaviour and material deterioration.
\end{abstract}

\section{Introduction}

One important part of the infrastructure for the urban civilisation are dams for flood protection, drinking water reservoirs or green energy production. Due to a high density of population, missing geographical meaningful places of location and high environmental standards a construction of new big dams in Europe and some other regions of the world is hardly possible. This and the necessity of using the available structures requires adequate maintenance and repair. Nowadays, rehabilitation of dams is mostly performed using ordinary shotcrete and anchored steel reinforcement mesh, the anchoring being a very time consuming and cost intensive process. Additionally, thick layers of concrete must be used to protect steel reinforcement against corrosion. An existing approach to improve serviceability and durability of hydraulic structures is to cover concrete joints with special synthetic material, which works fine under water, but has various problems with the solar radiation in the range between low and high water level. Caused by the modern use of those kind of basins with the high frequency of putting electric energy to the power network this water change zone becomes quiet big; in the project at hand it was more than $50 \%$ of the dam height. One promising alternative to the conventional approaches mentioned above is the use of SHCC. This class of materials seems to be appropriate to cover the upstream face of concrete walls providing water tightness.

The spraying process of fibre reinforced mortar or concrete is a challenge. Often fibres agglomerate and plug parts of the spraying equipment. Nevertheless, some authors have shown that SHCC can be applied as shotcrete $[6,7,8]$. These works were performed to strengthen masonry and increase the shear and earthquake resistance. Fine multiple cracking of the strengthening layer was reported.

The article at hand reports on the material behaviour with regard to the crack pattern under tensile loading and the water penetration resistance found by radio neutron radiography. In addition, the production process of the rehabilitation work at a pumped storage basin and the effectiveness of the protection layer over several years is shown.

\section{Material}

\subsection{Composition and mechanical behaviour under laboratory conditions}

For the demonstration project, an SHCC composition very similar to that developed earlier at the TU Dresden was chosen. The mechanical properties of the reference material under monotonic and cyclic loading were investigated first by Jun and Mechtcherine [9], and

* Corresponding author: mechtcherine@tu-dresden.de 
eventually by Müller and Mechtcherine [12]. Additionally, Altmann et al. [11] addressed the durability performance of the SHCC, while the first large-scale tension tests were performed by Mündecke and Mechtcherine [3]. Furthermore, mechanical properties under elevated temperatures were investigated at different strain rates $[10,13]$.

Table 1 shows the mix composition. The binder was a combination of Portland cement type I $42.5 \mathrm{R}$ and fly ash. In the previous work, fine graded quartz sand with a particle size from 0.06 to $0.20 \mathrm{~mm}$ was used as aggregate. The limitation of the aggregate size is necessary to achieve a uniform fibre distribution. In order to obtain a good workability and a fine fibre distribution as well as to prevent bleeding of the mixture, a superplasticizer and a viscosity agent were added. All adjustments concerning the flowability of the mix were controlled by the specific amount of superplasticizer. Furthermore, the SHCC under investigation contained 2 $\%$ by volume of PVA fibre with a length of $12 \mathrm{~mm}$ and a diameter of $40 \mu \mathrm{m}$. In the dam wall repair project all dry components except fibres were delivered as premix to the construction side.

Table 1. Composition of the SHCC

\begin{tabular}{lc}
\hline Component & {$\left[\mathbf{k g} / \mathbf{m}^{3}\right]$} \\
\hline Cement CEM I 42.5 R & 505 \\
Fly ash & 621 \\
Quartz sand & 536 \\
Water & 338 \\
Superplasticizer & 10 \\
Viscosity agent & 4.8 \\
\hline PVA fibres & 26
\end{tabular}

Test samples of this mix composition after storing for 28 days under laboratory conditions typically show appropriate mechanical properties with moderate tensile strength and ductile behaviour due to multiple cracking. The first crack strength of the matrix in direct tensile tests is $3.5 \mathrm{MPa}$ and the tensile strength is close to 5 MPa. Typically a strain capacity of $3 \%$ can be reached, see Figure 10.

\subsection{Water penetration resistance}

Under tensile stress, SHCC forms a finely distributed crack pattern with very narrow individual cracks. Thus, a protection layer made of SHCC can make a significant contribution to the reduction of ingress of water and other deteriorating media in the existing old concrete structures. To prove this hypothesis, composite specimens made of steel reinforced concrete and strengthened with an SHCC layer were characterized according to their water uptake and drying kinetics by neutron radiography imaging [14]. The authors of this study used the same SHCC mix design to perform their investigation, so the results can be transferred directly. During the investigation specimens pre-cracked in 4point-bend tests were retrofitted with SHCC and eventually cracked again. This led to a finer distributed crack pattern on the surface in comparison to the reference. The specimens were placed in a water bath with the cracked surface downwards. The image evaluation from neutron radiography revealed that the capillary suction was relatively high. Already after 1.2 min the cracks were filled with water and the transport in the uncracked matrix began. In cases of similar crack widths between substrate and repair layer, sufficient water could be transported into the substrate crack, so that hardly any improvement in the water tightness of the construction could be achieved. If the crack widths in the substrate were significantly larger than those in the repair layer, only a small amount of water could be added to the substrate crack and the overall transport volume can be reduced. The investigations of Schröfl et al. [14] additionally showed that hydrophobing of cracks in the substrate before the retrofitting can bring a significant reduction in the water uptake with it, since the capillary action of the substrate cracks would weaken. In the case of the planned retrofitting project, the cracks in the substrate were so pronounced that a sufficient reduction in water intake could be assumed due to smaller crack widths in the SHCC repair layer.

\section{Dam wall retrofitting}

\subsection{Dam location and technical data}

The dam renovation was performed on a water leaking concrete casting block joint of the water power plant Hohenwarte II in Thüringen, Germany. This power plant works as a pumped storage hydraulic power station. The upper basin was erected between 1957 and 1961 with two concrete dams and a dump stone wall. It contains up to 3 million $\mathrm{m}^{3}$ water and produces up to 317.8 MW electrical power [15]. Typical signs of deterioration on the concrete block walls were cracks, spalling and leaky joints. During a water free maintenance break in the year 2011, the block joint $37 / 38$ was repaired with sprayed SHCC. The renovated area had a height of about $17 \mathrm{~m}$ and a width of $3.5 \mathrm{~m}$. The layer thickness was 30 to $50 \mathrm{~mm}$ on the wall surface and up to $120 \mathrm{~mm}$ in the area of the deteriorated joint. The substrate was prepared with a high-pressure waterjet to remove loose particles and enable a good bond between the SHCC repair layer and the substrate.

\subsection{Mixing of shotcrete SHCC}

When producing SHCC for shotcrete application all dry components were premixed off-side using a 601 laboratory single-shaft mixer with adjustable rotation speed. The same mixer was transported to the construction side, where a defined volume of premix was filled in it followed by water and superplasticiser. After a mixing time of $1 \mathrm{~min}$ the pre-balanced fibre portion was added. The ready mix was filled directly into the pump, see Figure 1b. 


\subsection{Placement of SHCC}

The placement of SHCC on the wall of the dam was performed by means of wet spraying technique, see Figure 2a. A construction site compatible plaster pump m-tec speedy P100 was used. The device has a volumetric mortar flow between 40 and $140 \mathrm{l} / \mathrm{min}$ and a transport capacity of $100 \mathrm{~m}$ length and $30 \mathrm{~m}$ height. The spraying process occurred with a renovation spraying device having a short nozzle with an inner diameter of $12 \mathrm{~mm}$. The sufficient width of this nozzle was essential to prevent clumping of fibres. The layer thickness for one spraying process step was set to 15 to $25 \mathrm{~mm}$. The last layer was levelled manually to achieve a smooth surface, see Figure $2 b$.
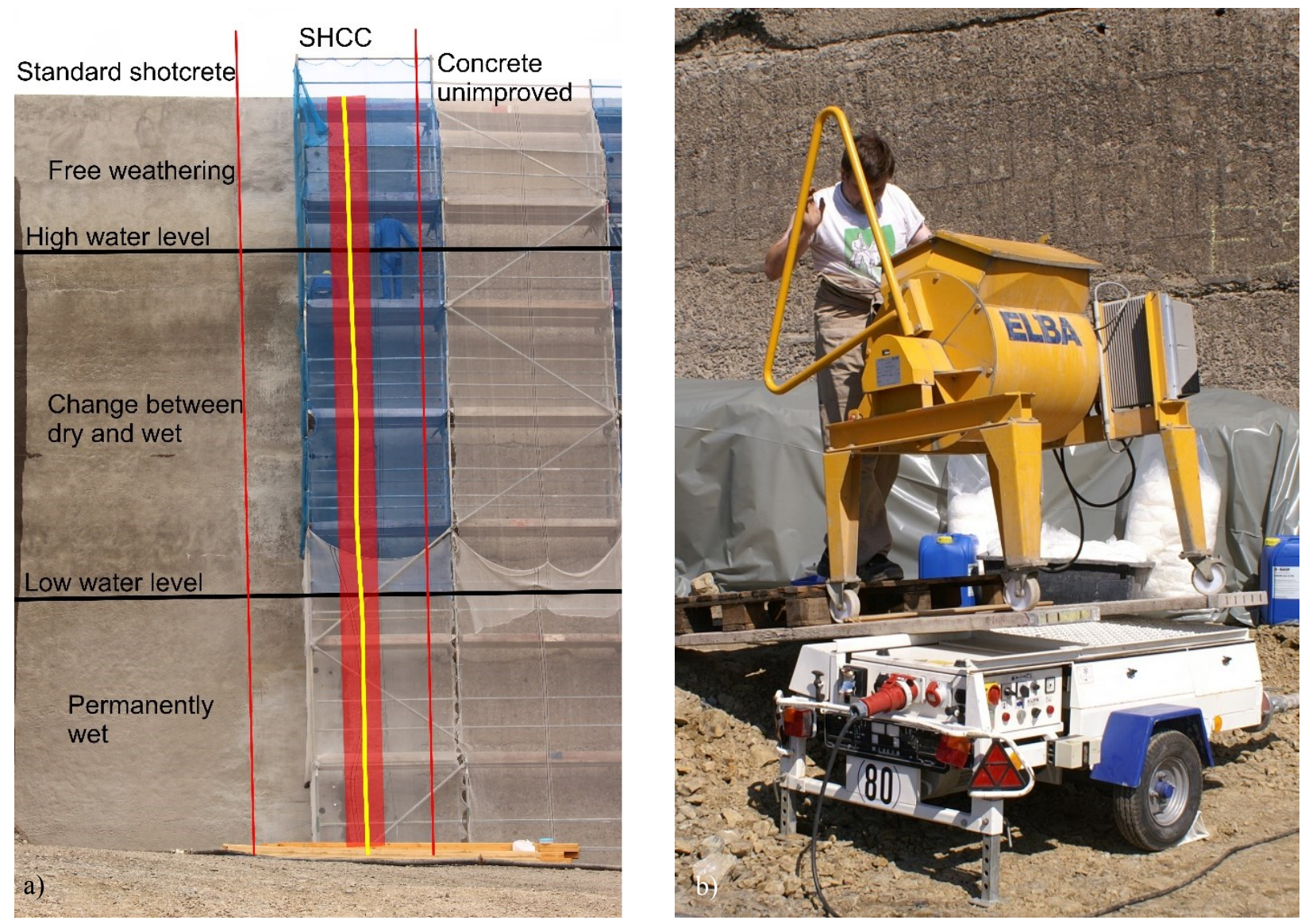

Fig 1. a) Overview of the block joint, b) mixing technology on-site: mixer is positioned above pumping device
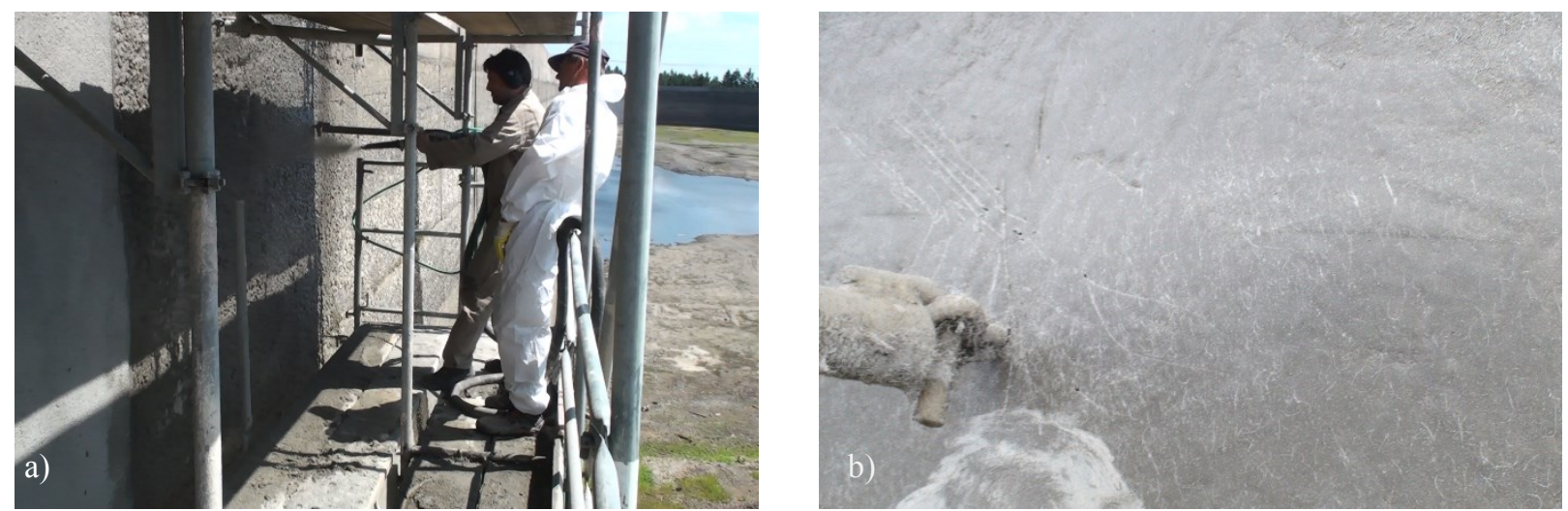

Fig 2. Shotcrete process: a) applying SHCC, b) detail of the levelled surface 


\section{Long-term observation}

In the dam wall repair project, no monitoring equipment was installed. However, four years after the repair the basin was emptied for some additional renovation works on other regions of the concrete wall. The area where the SHCC layer had been applied was equipped with a scaffolding, which allowed a visual inspection of the retrofitted zone as well as taking samples. The gained results proved that shotcrete SHCC performed according to the expectations. Branching and fine pattern of several cracks above the block joint in the old concrete could be determined at several horizontal joints. The water intake and, in particular, the penetration of dirt as it was in the non-maintained state was significantly reduced.

Additionally, several drill core specimens were taken to study the crack distribution in the SHCC layer and the concrete substrate below. Figure 3 shows one of the samples; in particular, a wide crack in the substrate and distributed cracking in the repair material can be observed.

Complementary to the observation of the crack development in repair layer the development of the mechanical properties of the material under free weathering was part of the research work. For this purpose, an additional test field was sprayed under the same conditions as described above. This wall was prone

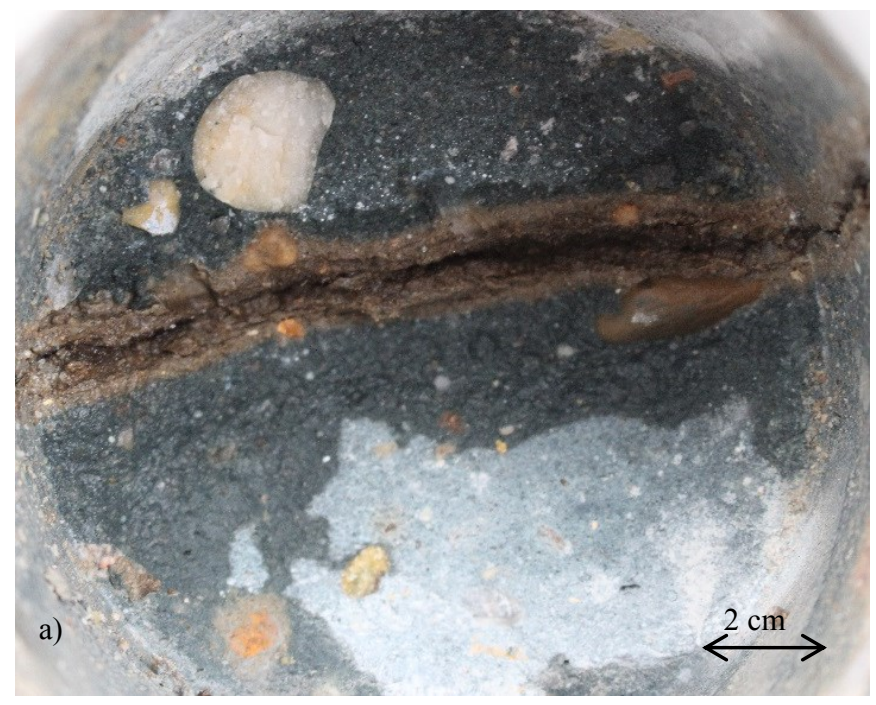

to free weathering for a time period of 5 years. Out of this test field different specimens were prepared and tested in 3 -point-bending. Figure $4 \mathrm{a}$ shows results of these tests in comparison to the results obtained from testing of specimens manufactured and stored under laboratory conditions and tested at an age of 14 days. Additionally, the mixture under investigation was tested in direct tension test. The results for two different testing ages, i.e. 28 days and 100 days, are displayed in Figure $4 \mathrm{~b}$.

Both performed tests show similar development of the mechanical performance of the SHCC. The tensile/flexural strength increases and the ductility decreases over time. The main reason for this time depending behavior can be found in the ongoing hydration process of binder in the matrix. Continuous hydration of cement and pozzolanic reactions of fly ash cause over time a denser and stronger matrix, which manifests among other things in the enhanced first crack stress. The enhanced matrix properties generate a higher bond between matrix and PVA fibre and hinder fibre pull-out. Both the higher matrix strength and the reduced free length of fibres caused by the higher bond strength are responsible for the reduction in the ductility.

This consideration is supported by photographs taken in the environmental scanning electron microscope (ESEM). Figure 5a shows a typical crack surface of

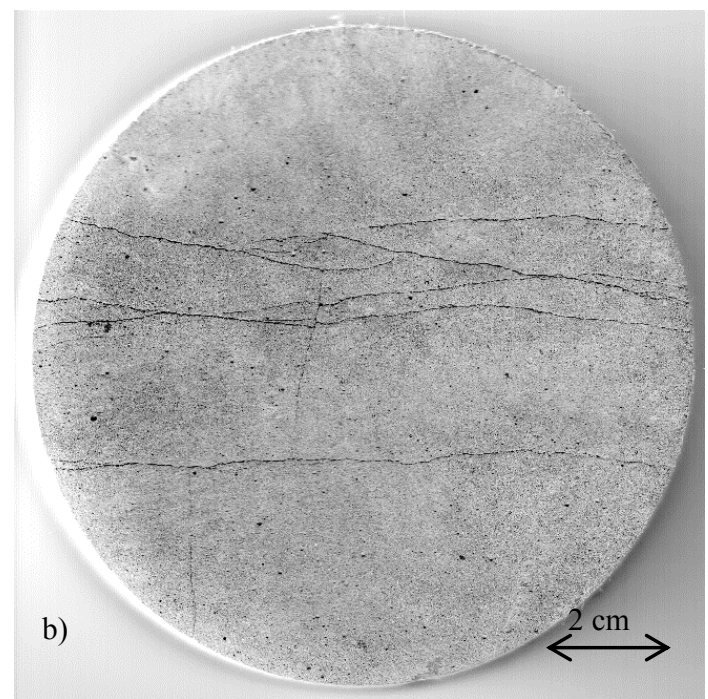

Fig 3. Horizontal block joint: a) crack in the substrate, $150 \mathrm{~mm}$ behind the surface, b) distributed cracking in the SHCC repair layer.

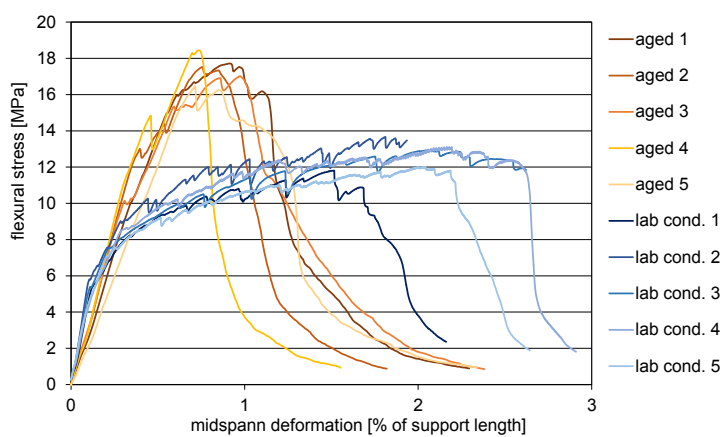

a)

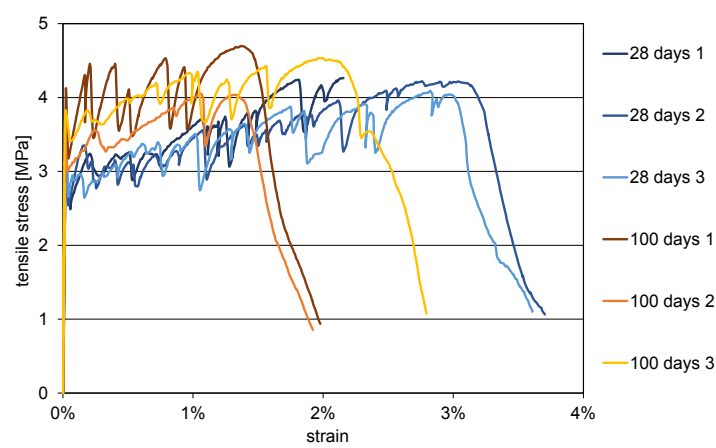

b)

Fig 4. Comparison of the mechanical performance of SHCC: a) bending test results for the same mixture stored under laboratory conditions and after 6 years exposure to free weathering, b) uniaxial tension test results for the material ages of 28 and 100 days 

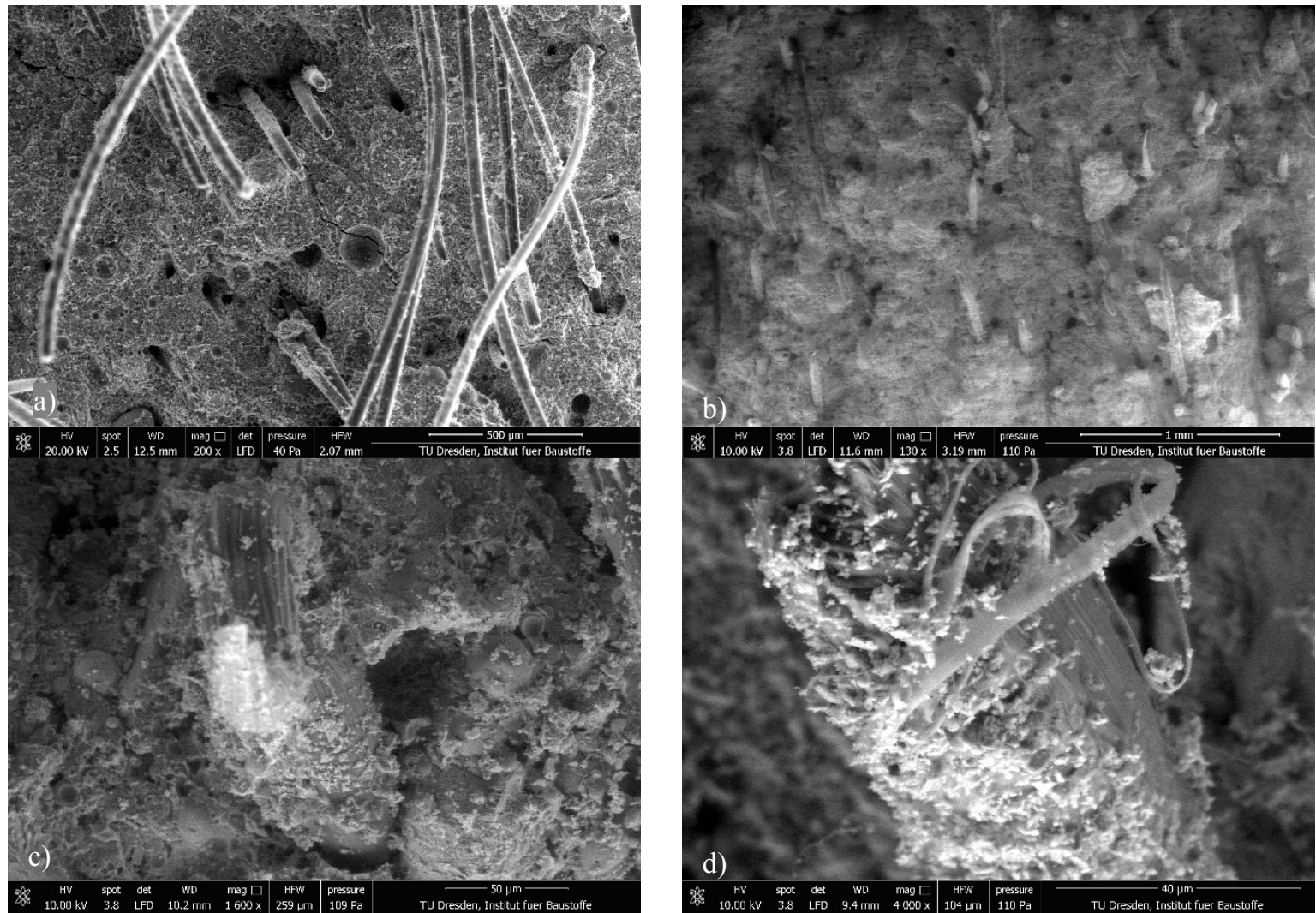

Fig. 5. Crack surface of SHCC a) stored under laboratory conditions and tested at the age of 28 days, b) tested at the age of 6 years of free weathering, overview c), d) details of ruptured fibres from picture b, numerous adhesion spots on the fibre surface.

SHCC stored under laboratory conditions and tested at the age of 28 days. The fibres' appearance indicate some adhesion of crystalline particles, but the main surface is clean while exhibiting some little scratches caused by the pull-out process. A different behaviour can be seen in Figures 10b to 10d: The majority of the fibres was pulled out only partially and then ruptured. The pullout effect is visible on shorter fibre endings and a number of empty fibre channels. The intense rupture can be explained by the pronouncedly enhanced adhesion of the matrix to the fibre surface, see little matrix fragments steaking to the fibres' surfaces. As a result, the bond to the matrix becomes stronger and the tendency to clamping increases.

Even if the overall performance was satisfactory, some potential for improvement could be identified. Due to the very pronounced unevenness in the joints' region, over the repair material [14]. Moreover, the matrix composition should be adapted to reduce the loss of ductility with increasing age of SHCC. Additionally, the self-healing capacity could not be observed in this project. In future projects, a crack monitoring system should be installed to collect detailed information of the crack opening and closing behaviour.

\section{Conclusions}

The shotcrete application of SHCC was tested on industrial scale under construction site conditions with a standard spraying technique. The requirement was a the positive properties of SHCC could not be fully utilized since the thickness differences were to pronounced which prevented a uniform stress distribution in the SHCC layer. As a consequence, formation of fine crack pattern was compromised to some extent. A further disadvantage of the uneven and very rough substrate was the tendency to conglomerating of fibers during SHCC spraying. As a result, the bond between substrate and SHCC layer was partly disturbed, which in turn may lead to stress peaks and irregularities in the repair layer. To avoid these problems, a smoothing of the substrate by plain mortar is suggested before the application of SHCC layer. Furthermore, a partial decoupling of the SHCC layer over the expansion joint is likely to promote multiple cracking, since this would introduce some free deformation length and may have a positive effect with respect to even stress distribution spraying machine with a more or less smooth tubing and a spraying nozzle having a sufficiently large diameter to prevent fibre conglomeration. The SHCC applied in the pilot project in Germany in the summer of 2011 as a repair layer of a dam wall proved to be functional over the period of 4 years (until the time of the first inspection). A well distributed crack pattern with narrow cracks over the wide block joint crack could be observed. The potential of the material could be used even better, if the pronounced unevenness and roughness of the concrete substrate would be reduced by applying a layer of plain mortar before placing SHCC. This would lead to a more uniform stress distribution in the repair 
layer, which would in its turn promote multiple cracking in the SHCC repair layer.

The authors would like to thank the AiF (German Federation of Industrial Research Associations) for the financial support of the project presented in the article at hand. Special thanks go to the staff of Dr. Waldenburger $\mathrm{GmbH}$, the practical partner for the shotcrete application. Furthermore, the support of Vattenfall AG, the owner of the water power plant, is acknowledged. Additionally, the authors gratefully acknowledge the lab team of the Institute of Construction Materials and the supporting students.

\section{References}

1. V. Mechtcherine (ed.), Ultra-ductile concrete with short fibres, development, testing, applications, ibidem Verlag, Stuttgart, 2005

2. V.C. Li, M. Lepech, Engineered Cementitious Composites: Design, Performance and Applications. Proc. Ultra-ductile concrete with short fibres, $V$. Mechtcherine (ed.), 99-120 (2005)

3. E. Mündecke, V. Mechtcherine, Untersuchung zum Tragverhalten von zugbeanspruchten Bauteilen aus hochduktilem Beton und Stahlbewehrung, Beton und Stahlbeton, 110, 220-227 (2015)

4. G. Van Zijl, F.H. Wittmann (eds.) Durability of Strain-Hardening Fibre-Reinforced Cement-Based Composites (SHCC) Volume 4, RILEM State-of-theArt-Reports, Springer Science \& Business Media (2010)

5. S. Qian, V.C. Li, H. Zhang, G. Keoleian, Life cycle analysis of pavement overlays made with Engineered Cementitious Composites, Cement \& Concrete Composites, 35 (2013)

6. M. A. Kyriakides, S. L. Billington, Seismic retrofit of masonry-infilled non-ductile reinforced concrete frames using sprayable ductile fiber-reinforced cementitous composites. Proc. The 14th world conference on earthquake engineering. Beijing, China; 1-7 (2008)

7. V. Mechtcherine, A.-E. Bruedern, T. Urbonas Strengthening/retrofitting of masonry by using thin layers of sprayed strain-hardening cement-based composites (SSHCC). Proc. 4th International conference on concrete repairs. Dresden, Germany 451-60 (2011)
8. ..W. Lin, L. Wotherspoon, A. Scott, J. M. Ingham In-plane strengthening of clay brick unreinforced masonry wallettes using ECC shotcrete, Engineering Structures, 66, 57-65 (2014)

9. P. Jun, V. Mechtcherine, Behaviour of Strainhardening Cement-based Composites (SHCC) under monotonic and cyclic tensile loading: Part 1 Experimental investigations, Cement and Concrete Composites, 32, 801-809 (2010)

10. V. Mechtcherine, F. A. Silva, M. Butler, D. Zhu, B. Mobasher, S.-L. Gao, E. Mäder, Behaviour of strain-hardening cement-based composites under high strain rates, Journal of Advanced Concrete Technology, 9(1), 51-62 (2011)

11. F. Altmann, J.-U. Sickert, V. Mechtcherine, M. Kaliske, A fuzzy-probabilistic durability concept for strain-hardening cement-based composites (SHCCs) exposed to chlorides: Part 1: Concept development, Cement and Concrete Composites, 34 (6), 754-762 (2012)

12. S. Müller, V. Mechtcherine, High-cycle fatigue of Strain-Hardening Cement-Based Composites (SHCC), Proc. SHCC3 - 3rd International RILEM Conference on Strain Hardening Cementitious Composites Dordrecht, TU Delft, 137-144 (2014)

13. V. Mechtcherine, F. A. Silva, S. Müller, P. Jun, R. Toledo Filho, Coupled strain rate and temperature effects on the tensile behavior of strain-hardening cement-based composites (SHCC) with PVA fibers. Cement and Concrete Research, 42, 1417-1427 (2012)

14. C. Schröfl, V. Mechtcherine, A. Kaestner, P. Vontobel, J. Hovind, Transport of water through strain-hardening cement-based composite (SHCC) applied on top of cracked reinforced concrete slabs with and without hydrophobization of cracks Investigation by neutron radiography. Construction and Building Materials, 76, 70-86 (2015)

15. Deutsches Talsperrenkomitee e.V.. Talsperren in Deutschland, Springer Vieweg (2013) 